\title{
Tingkat KaPABILITAS Tata Kelola TeKNOLOGI INFORMASI PADA DOMAIN EVALUATE, DIRECT, AND MONTORING
}

\author{
Supriyadi Dauwango, Salahudin Olii ${ }^{*}$
}

Program Studi Sistem Informasi, Jurusan Teknik Informatika, Fakultas Teknik, Universitas Negeri Gorontalo, Indonesia

*Penulis korespondensi, email: salahudin@ung.ac.id

\begin{abstract}
AbSTRAK
Universitas Negeri Gorontalo (UNG) saat ini sudah menerapkan Teknologi Informasi (TI) dalam menjalankan tujuan bisnis organisasi sesuai dengan visi dan misi. Namun, untuk memastikan keselarasan strategi TI dan strategi bisnis organisasi yang sesuai dengan tujuan organisasi perlu adanya analisis tingkat kapabilitas dalam penerapan TI. Tujuan penelitian ini adalah mengukur tingkat kapabilitas proses TI di UNG. Metode yang digunakan adalah metode deskriptif yang menggunakan data kuantitatif dan kualitatif serta teknik pengumpulan data melalui kuesioner, wawancara dan studi kepustakaan. Penelitian ini menggunakan COBIT 5 pada domain EDM (Evaluate Direct and Monitor) meliputi EDM03, EDM04 dan EDM05. Hasil penelitian menunjukkan bahwa tingkat kapabilitas dalam mengelola TI secara keseluruhan rata-rata berada pada level 3 yang berarti proses-proses TI sudah diterapkan dikelola dan dipertahankan sesuai dengan standar yang ada, Rekomendasi yang diberikan adalah perlu adanya SOP terhadap evaluasi manajemen resiko, penambahan sumber daya TI dan komunikasi yang efektif terhadap pengelolaan TI di UNG.
\end{abstract}

Kata kunci: COBIT 5, strategi bisnis, tata kelola TI

\begin{abstract}
Universitas Negeri Gorontalo has implemented the information technology (IT) system in managing the business goal of the organization in accordance with the vision and mission of the institution. However, an analysis of the capability level of IT implementation requires sync between the strategy of IT and business strategy of the organization based on the institution's objective. The objective of this study is to examine the capability level of the IT governance in Universitas Negeri Gorontalo. The data of this descriptive study comprised both qualitative and quantitative data; these were from the questionnaire, interview, and library research. This present study used COBIT 5 on EDM domain; the domain involved EDM03, EDM04, and EDM05. The results show that the capability level of IT governance is at level 3 on average, meaning that the processes of IT have been implemented and managed according to the standard. Nevertheless, it is recommended to design a standard operating procedure on the evaluation of risk management, add IT resources, and conceptualize effective communication of IT management.
\end{abstract}

Keywords: COBIT 5, business strategy, IT governance 


\section{Pendahuluan}

Saat ini tata kelola teknologi informasi (TI) telah diterapkan oleh banyak organisasi sebagai strategi terciptanya tata kelola TI yang baik. Walaupun demikian, penerapan TI yang dilakukan tanpa mempertimbangakan kebutuhan organisasi secara menyeluruh dapat mengakibatkan penerapan yang dilakukan tersebut kurang efektif, karena tidak dapat memenuhi secara menyeluruh semua aspek dalam organisasi bahkan penerapan yang dilakukan tersebut tidak sesuai dengan kondisi yang diharapkan dan tidak tepat sasaran. Tata kelola TI berfungsi untuk menyelaraskan strategi TI dengan strategi organisasi. Keselarasan ini sangat penting karena memungkinkan organisasi untuk dapat merespon lebih cepat terhadap kondisi di lingkungan bisnis organisasi. Penyebab utama dari kegagalan suatu organisasi adalah kurangnya analisis dan tata kelola yang baik di organisasi tersebut (Amali \& Katili, 2018), sehingga tata kelola yang baik sangat diperlukan dalam organisasi untuk memastikan kesesuaian antara strategi TI dengan strategi organisasi.

Universitas Negeri Gorontalo (UNG) merupakan suatu organisasi pendidikan tinggi yang telah menerapkan TI dalam menjalankan tujuan proses bisnisnya, diantaranya sistem informasi akademik, sistem informasi keuangan, sistem informasi penerimaan mahasiswa baru, sistem arsip administrasi, sistem informasi lembaga penelitian pengabdian masyarakat, dan sistem informasi tata usaha. Berdasarkan observasi yang dilakukan terdapat beberapa masalah yang ditemukan pada penerapan TI yang dilakukan satu diantaranya adalah pada sistem informasi akademik terpadu (SIAT) yang kinerjanya belum optimal dan juga belum sesuai dengan yang diharapkan. Selain itu, tidak terdapat suatu indikator yang menyatakan bahwa penerapan tata kelola TI di UNG selama ini telah sesuai dengan tujuan yang ingin dicapai (Tim TIK UNG, 2016).

Tata kelola TI adalah proses yang memastikan bahwa pengelolaan TI selaras dengan tujuan dan pengembangan strategi bisnis suatu perusahaan atau organisasi yang merupakan tanggungjawab direksi, manajemen eksekutif dan manajemen TI (ITGI, 2007). Selain itu, tata kelola TI adalah suatu struktur hubungan dan proses untuk mengatur dan mengontrol organisasi yang bertujuan untuk mencapai tujuan organisasi yang telah ditetapkan dengan pertambahan nilai dengan tetap menyeimbangkan resiko-resiko dengan nilai yang didapatkan dari penerapan TI dan proses-prosesnya (Surendro, 2008). Menurut menurut ITGI (2007) tujuan tata kelola TI adalah mengontrol penggunaannya dalam memastikan bahwa kinerja TI memenuhi dan sesuai dengan tujuan sebagai berikut:

1. Menyelaraskan TI dengan strategi organisasi serta manfaat yang dapat direalisasikan dari penerapan TI.

2. Penggunaan TI memungkinkan organisasi menggunakan peluang, serta memaksimalkan keuntungan dari penerapan TI.

3. Bertanggungjawab terhadap penggunaan sumber daya TI.

4. Manajemen resiko yang ada terkait TI perlu dijaga dengan baik.

Tujuan penelitian ini adalah mengukur tingkat kapabilitas proses tata kelola TI, dengan menggunakan framework COBIT 5 pada domain EDM khususnya pada EDM03, EDM04 dan EDM05. COBIT merupakan kerangka panduan tata kelola TI yang digunakan untuk menjembatani gap antara kebutuhan dan bagaimana teknis pelaksanaan pemenuhan kebutuhan tersebut dalam suatu organisasi. COBIT memungkinkan pengembangan kebijakan yang jelas dan sangat baik digunakan untuk kontrol TI di organisasi, membantu meningkatkan kualitas dan nilai serta menyederhanakan pelaksanaan alur proses sebuah organisasi dari sisi penerapan TI. COBIT dikembangkan oleh IT Governance Institute (ITGI) yang merupakan bagian dari Information System Audit and Control Association (ISACA, 2012). 
COBIT 5 adalah sebuah kerangka kerja untuk tata kelola dan manajeman TI dan semua yang berhubungan, yang dimulai dari memenuhi kebutuhan stakeholder akan informasi dan teknologi (ISACA, 2012a). COBIT 5 memiliki 2 (dua) area utama yaitu area tata kelola (Governance) terkait dengan hal-hal yang mendasari pengelolaan melalui pendefinisian strategi dan kontrol dan terdiri dari lima proses dalam domain EDM, dan area manajemen (Management) terkait dengan bagaimana tata kelola tersebut dilaksanakan sesuai dengan cakupan dari pengelolaan yang dilakukan melalui perencanaan taktis yang terdiri atas empat domain utama yang bertanggung jawab pada area Plan, Build, Run and Monitor (PBRM).

EDM berhubungan dengan tujuan stakeholder dalam melakukan penilaian, optimalisasi resiko dan sumber daya, mencakup praktek dan kegiatan yang bertujuan untuk mengevaluasi pilihan strategis, serta memberikan arahan kepada TI dan memantau hasilnya. Domain ini terdiri dari 5 proses yaitu EDM01 (Ensure Governance framework setting and maintenance), EDM02 (Ensure Benefits Delivery), EDM03 (Ensure Risk Optimisation), EDM04 (Ensure Resource Optimisation) dan EDM05 (Ensure Stakeholder Transparency).

Adapun penilaian proses kapabilitas pada COBIT 5 berdasarkan pada ISO/IEC 15504 (standar mengenai Software Engineering dan Process Assessment). Proses ini mengukur performansi tiap-tiap proses tata kelola (EDM-based) dan dapat mengidentifikasi area-area yang perlu untuk ditingkatkan performansinya. Penilaian proses kapabilitas dalam penelitian ini terkait dengan penanganan resiko TI, ketersediaan sumber daya, optimalisasi sumber daya yang ada di organisasi serta sejauh mana komunikasi yang terjalin kepada para stakeholder terkait dengan penerapan TI yang dilakukan.

Tingkat kapabilitas merupakan sebuah model yang menggambarkan bagaimana suatu proses inti di dalam organisasi berjalan. Gambaran ini dibutuhkan untuk mengetahui proses mana saja yang sudah berjalan sesuai dengan harapan dan proses mana saja yang masih kurang sehingga membutuhkan perhatian dan perbaikan secara khusus. Gambaran ini juga menyediakan pengukuran performance atau kinerja dari proses-proses pada area governance maupun manajemen.

Terdapat enam level kapabilitas proses yang dapat dicapai (ISACA, 2012a), yaitu:

1. Level 0 (Incomplete Process) proses yang belum lengkap. Proses ini tidak dilaksanakan atau gagal untuk mencapai tujuan prosesnya.

2. Level 1 (Performed Process) performa proses. Proses dilakukan dan mencapai tujuan prosesnya.

3. Level 2 (Managed Process) proses yang dilakukan sekarang dan diimplementasikan, dikelola, dimonitor, dan disesuaikan dan produk yang tepat dipertahankan dan juga dikendalikan.

4. Level 3 (Enablished Process) proses yang dikelola sebelumnya kini diimplementasikan menggunakan proses yang mampu mencapai prosesnya.

5. Level 4 (Predictable Process) proses yang berjalan dan ditetapkan sekarang beroperasi dalam mendefinisikan batas untuk mencapai hasil prosesnya.

6. Level 5 (Optimising Process) proses diprediksi dan dijelaskan sebelumnya terus ditingkatkan guna memenuhi tujuan bisnis yang relevan saat ini.

\section{METODE}

Penelitian ini menggunakan pendekatan deskriptif kuantitatif dan kualitatif (Creswell, 2009) Analisis deskriptif bertujuan untuk mendeskripsikan tingkat kapabilitas tata kelola TI di UNG berdasarkan framework domain EDM. Langkah-langkah dalam penelitian ini mengikuti Metode Assessment Process Activities pada Cobit 5 (ISACA, 2012a) seperti ditunjukkan pada Gambar 1 (Dauwango, 2019). 


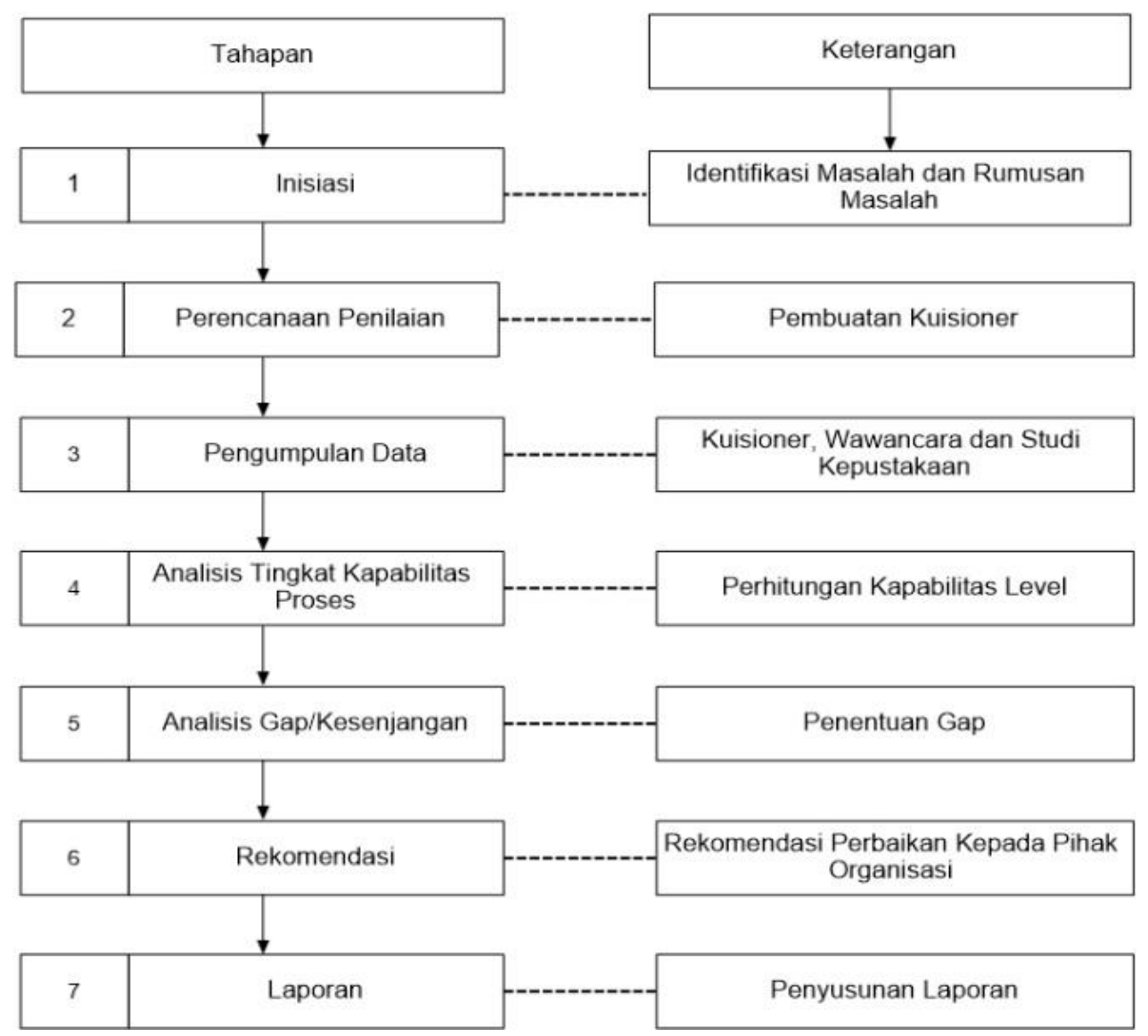

Gambar 1. Prosedur penelitian

Jenis data yang digunakan dalam penelitian ini adalah jenis data kuantitatif dan kualitatif. Data kuantitatif diperoleh melalui hasil penilaian kuisioner sedangkan data kualitatif diperoleh dari hasil wawancara. Penentuan responden diperoleh melalui hasil identifikasi tugas dan tanggung jawab dari setiap responden dengan mengacu pada Responsible, Accountable, Consulted, Informed (RACI) sesuai dengan subdomain masing-masing proses. Kuesioner yang disebarkan dalam penelitian ini sebanyak 100 kuesioner. Akan tetapi, jumlah kuesioner yang dikembalikan dan digunakan sebanyak 57 kuesioner yang telah diisi oleh responden. Menurut Baley (2007) bahwa untuk penelitian yang menggunakan analisis data statistik, ukuran sampel paling minimum adalah 30. Sehingga jumlah kuisioner yang ada sudah memenuhi standar kelayakan dalam pengolahan data.

Pengumpulan data melalui wawancara dilakukan untuk melengkapi data dalam rangka identifikasi permasalahan yang ada di organisasi (Agoan dkk, 2017). Dalam penelitian ini, kegiatan wawancara dilakukan untuk mengetahui kondisi penerapan TI dan untuk melengkapi data yang diperoleh serta menguji kebenaran data tersebut. Adapun yang menjadi subjek penelitian adalah Direktur Pustikom, Kabag Pustikom dan Staf Divisi Sistem Informasi. Jenis wawancara yang dilakukan adalah focuses interview, yaitu wawancara yang dilakukan dalam waktu singkat dalam suasana yang tidak formal dengan pertanyaan-pertanyaan yang terkait dengan tata kelola TI. Dalam penelitian ini digunakan COBIT 5 sebagai acuan skala pengukuran instrumen, sedangkan analisis data dilakukan untuk mengidentifikasi capability level, menemukan gap dan menentukan rekomendasi.

Teknik analisis data menggunakan teknik analisis data deskriptif dengan langkah-langkah sebagai berikut: 1) data dianalisis berdasarkan hasil kuesioner tingkat kapabilitas proses. Dari temuan-temuan yang dijabarkan tersebut dihasilkan kemampuan tata kelola TI yang ada saat 
ini, 2) pada tahap ini dilakukan analisa gap dan mendefinisikan target untuk perbaikan dari hasil analisa gap pada hasil kuesioner capability level yang diberikan. Pada tahap ini dijelaskan target kemampuan yang ingin dicapai oleh organisasi, mengacu pada Process Assessment Model yang terdiri dari level 0 sampai dengan level 5. Target maksimal pencapaian tingkat kemampuan organisasi adalah level 5.

\section{HASIL DAN DISKUSI}

\section{Analisis Tingkat Kapabilitas Proses (Process Capability Levels)}

Analisis tingkat kapabilitas proses dilakukan untuk mengukur tingkat kapabilitas proses TI di UNG. Analisis yang dilakukan mengacu pada domain EDM dengan subdomain EDM03, EDM04 dan EDM05 berdasarkan hasil dari kuesioner yang telah diperoleh dari responden. Perhitungan ini menentukan indeks dari masing-masing kriteria. Tabel 1 menunjukkan pengukuran yang dilakukan dari setiap domain.

Tabel 1. Tingkat kapabilitas domain EDM

\begin{tabular}{clccc}
\hline \multirow{2}{*}{ Domain } & \multicolumn{1}{c}{ Proses } & $\begin{array}{c}\text { Current } \\
\text { Capability }\end{array}$ & $\begin{array}{c}\text { Expected } \\
\text { Level }\end{array}$ & Gap \\
\hline EDM03 & Memastikan optimalisasi resiko & 3,16 & 4 & 0,84 \\
EDM04 & Memastikan optimalisasi sumber daya & 3,33 & 4 & 0,67 \\
EDM05 & memastikan transparansi terhadap stakeholder & 3,34 & 4 & 0,66 \\
\hline
\end{tabular}

Berdasarkan hasil yang diperoleh dari perhitungan capability level yang digunakan pada proses EDM03, EDM04 dan EDM05 dapat disimpulkan sebagai berikut:

1. Nilai capability level saat ini pada proses EDM03 (optimalisasi resiko TI) tingkat kematangan saat ini pada level 3 dengan nilai kematangan 3.16.

2. Pada proses EDM04 (optimalisasi resiko sumber daya TI) tingkat kematangan saat ini pada level 3 dengan nilai kematangan 3.33.

3. Pada proses EDM05 (memastikan Tranparansi terhadap stakeholder) tingkat kematangan saat ini pada level 3 dengan nilai kematangan 3,34.

Hasil di atas digunakan sebagai acuan awal untuk menentukan tingkat kematangan saat ini. Selanjutnya dilakukan analisis gap untuk menentukan sejauh mana tingkat kematangan tata kelola TI yang ada dengan kondisi yang ingin dicapai. Current Capability merupakan nilai ratarata dari tingkat kematangan yang sebenarnya (as-is) pada proses EDM03, EDM05 dan EDM05, sedangkan Expected Capability merupakan nilai dari tingkat target kematangan yang diharapkan (to-be) pada ketiga proses yang berjalan di UNG. Untuk mencapai tingkat kematangan sesuai dengan yang diharapkan, maka perlu adanya penyesuaian agar tingkat kematangan yang diharapkan dapat terwujud.

\section{Analisis Kesenjangan (Gap)}

Tingkat kematangan pada proses EDM03, EDM04 dan EDM05 sesuai dengan Tabel 1 berada di level 3 (Established Process). Gap setiap domain ini dijelaskan sebagai berikut:

1. EDM03 (Memastikan optimalisasi resiko)

Tingkat kapabilitas pada proses EDM03 berada pada level 3 (established process) yang berarti bahwa proses EDM03 telah dilakukan, aktivitas optimalisasi resiko sudah dijalankan, dikelola dan dipertahankan yang berguna untuk memastikan bahwa resiko yang ada pada pengelolaan TI dapat diidentifikasi. Nilai kematangan yaitu 3,16 dan level target yang ingin dicapai adalah level 4 (predictable process). Proses ini menjelaskan evaluasi manajemen resiko dilakukan secara rutin oleh Pustikom UNG utamanya berkaitan 
infrastruktur TI yang digunakan. Tindakan evaluasi juga biasanya dilakukan pada setiap tahun anggaran yang disesuaikan dengan hasil evaluasi terhadap kondisi infrastrukur TI yang digunakan masih sesuai dengan kebutuhan atau perlu adanya penambahan peralatan. Namun, tindakan evaluasi manajemen resiko yang dilakukan selama ini belum diatur dalam standar operasional prosedur (SOP).

Dalam penanganan resiko terkait dengan permasalahan di bidang TI, Pustikom selaku unit kerja yang bertanggungjawab dalam memberikan layanan di bidang TI selalu berupaya melakukan penanganan secara langsung dengan cepat dan tepat. Akan tetapi, keterbatasan jumlah personil yang ada mempengaruhi kinerja Pustikom termasuk dalam hal penanganan resiko yang mengakibatkan terjadinya keterlambatan dalam penanganan resiko yang dilakukan, karena tidak seimbangnya jumlah personil dengan jumlah pengguna yang ada di organisasi. Kemampuan memantau/monitoring manajemen resiko selalu dilakukan oleh Pustikom secara rutin untuk mengidentifikasi ataupun mengantisipasi permasalahan yang akan terjadi terhadap infrastrukur TI, tindakan yang dilakukan dalam memantau manajemen resiko misalnya memonitoring kinerja server yang dilakukan secara langsung.

2. EDM04 (Memastikan optimalisasi sumber daya)

Tingkat kapabilitas pada proses EDM04 berada pada level 3 (established process) yang berarti bahwa proses EDM04 dilakukan, aktivitas optimalisasi sumber daya TI sudah dijalankan, dikelola dan dipertahankan yang berguna untuk memastikan bahwa sumber daya TI yang ada dapat berjalan secara optimal. Nilai kematangan yaitu 3,33 dan level target yang ingin dicapai adalah level 4 (predictable process).

Proses ini menjelaskan dalam melakukan evaluasi terhadap sumber daya, Pustikom selalu memastikan bahwa infrastuktur TI yang digunakan dapat beroperasi sesuai dengan fungsinya. Sehingga, Pustikom selalu melakukan pemantauan ataupun perawatan terhadap peralatan TI yang dilakukan secara rutin. Untuk itu, tindakan yang dilakukan ialah mengupayakan adanya personil yang bertanggungjawab dalam melakukan perawatan, menguasai dan mengoperasikan peralatan TI yang digunakan, sehingga peralatan dapat bekerja secara optimal.

Infrastruktur TI yang ada saat ini cukup memadai, namun sumber daya manusia (SDM) masih terbatas. Hal ini mengakibatkan beberapa kendala akibat tidak seimbangannya sumber daya TI dengan pengguna yang mengakibatkan layanan yang diterima belum optimal. Adapun pihak Pustikom selalu melakukan tindakan monitoring/pengawasan terhadap infrastruktur TI secara langsung dan belum menggunakan tools yang biasa digunakan oleh organisasi dibidang TI.

3. EDM05 (Memastikan tranparansi terhadap stakeholder)

Tingkat kapabilitas pada proses EDM05 berada pada level 3 (established process) yang berarti bahwa proses EDM05 dilakukan, aktivitas transparansi terhadap stakeholder sudah dijalankan, dikelola dan dipertahankan yang berguna untuk memastikan koordinasi terhadap para pemangku kepentingan dilakukan secara efektif. Nilai kematangan yaitu 3,34 dan level target yang ingin dicapai adalah level 4 (Predictable Process).

Dalam proses ini, Pustikom selaku unit kerja di bidang TI selalu melakukan evaluasi untuk infastrukur TI dan juga SDM yang ada. Tetapi, tindakan evaluasi untuk infrastuktur TI yang dilakukan saat ini belum didokumentasikan dalam catatan pelaporan, sehingga kondisi peralatan TI yang digunakan saat ini tidak teridentifikasi secara mendetail. Selain itu, Pustikom selalu berupaya untuk melakukan koordinasi maupun komunikasi kepada para pengguna untuk memaksimalkan layanan yang diberikan, baik melalui telpon, surat, ataupun melalui customer service di bagian pelayanan. Namun, belum ada tindakan untuk 
mengidentifikasi solusi yang berguna dan mengantisipasi agar setiap permasalahan yang terjadi tidak terulang lagi dikemudian hari.

\section{Rekomendasi}

Berdasarkan hasil temuan dan gap yang diperoleh mengenai nilai antara tingkat kematangan saat ini dengan tingkat kematangan yang diharapkan, maka dapat disimpulkan bahwa semua proses memiliki gap, sehingga perlu ada solusi perbaikan untuk tata kelola TI agar mencapai tingkat level yang diharapkan. Berikut rekomendasi yang dilakukan:

1. Membentuk tim khusus yang memiliki keterampilan dalam melakukan tindakan mengidentifikasi resiko TI.

2. Melakukan monitoring dan evaluasi terhadap sistem aplikasi yang digunakan agar mampu melakukan penanganan awal apabila terjadi masalah atau resiko TI yang ada.

3. Mendokumentasikan resiko dan kendala TI secara tertulis sebagai bentuk pelaporan kepada stakeholder sebagai bahan pertimbangan dalam mengambil keputusan.

4. Perlu adanya penambahan jumlah personil atau tenaga teknis yang mampu mengelola dan mengoperasikan infrastukrtur sumber daya yang ada, juga untuk mengimbangi jumlah pengguna yang cukup besar sehingga pelayanan yang diberikan akan diterima secara maksimal.

5. Perlu adanya dokumentasi atau tools seperti:

a. Nagios: Tool untuk memantau hampir semua jenis komponen seperti protokol jaringan, sistem operasi, sistem metrik, aplikasi, layanan, web server, website, dan lain-lain.

b. Ganglia: Tool untuk memonitoring server clutser, network management dan menyediakan analisis bagaimana mesin/komputer berjalan bersama-sama.

c. Zabbix: Tool untuk memantau segala sesuatu dari kinerja dan ketersediaan server, peralatan jaringan untuk aplikasi web dan database. Tool ini juga dapat memonitoring kondisi infrastukutur TI yang digunakan untuk mengantisipasi terhambatnya kinerja infrastruktur ataupun sebagai bahan pertimbangan dalam pengambilan keputusan.

6. Perlu adanya penambahan infrastruktur untuk mengimbangi bertambahnya jumlah pengguna.

7. Memberikan pelaporan terhadap kondisi TI secara berkala kepada penentu kebijakan sehingga dapat diambil kebijakan yang mengarah pada mengupayakan pengelolaan TI dapat bekerja secara optimal.

\section{KESIMPULAN}

Berdasarkan hasil analisis diperoleh bahwa tingkat kapabilitas TI pada domain EDM berada pada level 3 yang berarti proses-proses sudah diterapkan dikelola dan dipertahankan sesuai dengan standar yang ada, namun pencapaian pada setiap prosesnya belum terpenuhi semuanya dan belum mencapai hasil yang diharapkan. Proses ini masih di bawah tingkat kapabilitas yang diharapkan (to-be) yaitu 4 (predictable process). Gap yang terjadi terletak pada kemampuan pengelola dalam mengoptimalisasi resiko, sumber daya, dan transparansi. Oleh karena itu perlu adanya tindakan yang lebih efektif dalam proses evaluasi manajemen resiko, diantaranya pembuatan SOP terhadap tindakan evaluasi manajemen resiko, sehingga setiap permasalahan dapat teridentifikasi dalam catatan pelaporan. Selain itu, penambahan infrastuktur TI, penambahan jumlah personil yang memiliki kemampuan di bidang TI, serta SOP dalam pengelolaan infrastuktur TI untuk meminimalisir terjadinya kendala yang terjadi. Di sisi lain koordinasi dan komunikasi yang efektif terhadap stakeholder terkait dengan penerapan TI juga sangat diperlukan. 


\section{REFERENSI}

Agoan, T. S., Hans. F. W. \& Stanley, K. (2017). Analisa Tingkat Kematangan Teknologi Informasi pada Dinas Komunikasi dan Informatika Kota Manado Menggunakan Framework COBIT 5 Domain EDM dan Deliver, Service and Support (DSS). Journal Teknik Informatika, 10(1), 1-9.

Amali, L. N. \& Katili, M. R. (2018). Identification of Influential Factors in Implementing IT Governance: A Survey Study of Indonesian Companies in the Public Sector. Interdisciplinary Journal of Information Knowledge, and Management (IJKM), 13, 61-77, https://doi.org/10.28945/3975.

Bailey A. C. (2007). A Gguide to Qualitative Field Research, Second Edition. New Delhi: Fine Forge Press.

Creswell, J. W. (2009). Research Design: Qualitative, Quantitative, and Mixed Methods Approaches (3rd ed.). California USA: Sage Publications.

Dauwango, S. (2019). Analisis Proses Tata Kelola TI Menggunakan Framework COBIT 5 Pada Domain Evaluate, Direct, and Monitoring (EDM). Skripsi. Universitas Negeri Gorontalo.

ITGI. (2007). Executive Overview COBIT 4.1. Rolling Meadows USA: IT Governance Institute

ISACA. (2012). COBIT 5 Enabling Processes.USA: IT Governance Institute

ISACA, (2012a). COBIT 5 A Business Framework For the Governance and Management Of Enterprise IT. USA: IT Governance Institute.

Nasir, M. (2011). Metode Penelitian. Jakarta: Ghalia Indonesia

Surendro, K. (2008). Rancangan Tata kelola Teknologi Informasi untuk Pabrik Pupuk. Jurnal Informatika, 9(2), 115-121.

Tim TIK UNG. (2016). Blueprint ICT UNG. Gorontalo: Universitas Negeri Gorontalo. 